\title{
Immunomodulatory effect of Quercetin on dysregulated Th1/Th2 cytokine balance in mice with both type 1 diabetes and allergic asthma
}

\author{
Nutakki Ravikumar*, Chilaka Naga Kavitha \\ Department of Pharmacology, GITAM Institute of Pharmacy, GITAM (Deemed to be University), Rushikonda, Visakhapatnam, India.
}

\section{ARTICLE INFO \\ Received on: 14/12/2019 \\ Accepted on: 16/01/2020 \\ Available online: 05/03/2020}

\section{Key words:}

Quercetin, Th1/Th2 balance, ovalbumin, comorbid diabetic asthma, allergic inflammation.

\begin{abstract}
T-helper subtype imbalance is intricate in type 1 diabetes (T1D) and asthma initiation. The role of quercetin in immune dysregulation in comorbid conditions of T1D and asthma is not available. In this study, it was thought worthy to evaluate the role of quercetin on modulating Th1/Th2 cytokine dysregulation in comorbid diabetic asthma. Male Balb/c mice were injected intravenously with alloxan $(80 \mathrm{mg} / \mathrm{kg})$ to persuade T1D. Succeeding diabetes introduction, two intraperitoneal sensitizing doses of ovalbumin emulsion ( $50 \mu \mathrm{g}$ ovalbumin blended with $2.5 \mathrm{mg}$ alum/sensitization) were given on days 3 and 8 . Mice were given intranasal challenges of ovalbumin ( $100 \mu \mathrm{g}$ ovalbumin/25 $\mu$ l of sterile saline) on days $13-15$. Oral quercetin treatment $(10-30 \mathrm{mg} / \mathrm{kg}$ ) was given daily on days $3-15$. Nasal hyperresponsiveness (NHR) was recorded immediately after Ova challenge on day 16. Bronchoalveolar lavage fluid (BALF), blood, and lungs were collected 1-hour post NHR for further analysis. Quercetin treatment significantly decreased eosinophils, interleukin-4 while increasing interferon-gamma in blood, and BALF and reduced the allergic airway inflammation by inhibiting inflammatory cell infiltration and mucous cell metaplasia. Furthermore, quercetin with a dose of $30 \mathrm{mg} / \mathrm{kg}$ demonstrated a significant glucose reduction. Thus, quercetin exerted dose-dependent anti-asthma activity by modulating Th1/Th2 balance with glucose-lowering potential in comorbid mice.
\end{abstract}

\section{INTRODUCTION}

Autoimmune type 1 diabetes and asthma result from a dysregulated balance of T-helper 1/T-helper 2 (Th1/Th2) immune responses. A simultaneous presentation of these two diseases in patients may disclose the involvement of few common pathophysiological mechanisms that mediate the immune dysregulation in these two conditions (Rottem and Shoenfeld, 2003). Autoimmune Th1 and Th2 responses are implicated in the development of type 1 diabetes (T1D) and allergic asthma, respectively (Metsala et al., 2018). However, few evidence indicate the role of Th1 in severe asthma exacerbations and Th2 in T1D pathophysiology (Rachmiel et al., 2006). The association between

"Corresponding Author

Nutakki Ravikumar, Department of Pharmacology, GITAM Institute of Pharmacy, GITAM (Deemed to be University), Rushikonda, Visakhapatnam, India.E-mail:nutakkiravi@yahoo.com the incidence of T1D and asthma is still a point of discussion, and the loss of immune system balance at early age due to the interaction between inherent susceptibility and environmental triggers may govern the development of these clinical diseases (Rachmiel et al., 2006; Stene and Nafstad, 2001; Zoka et al., 2013). Cardwell et al. (2003) reported a decrease of asthma occurrence in T1D patients from a meta-analysis of clinical literature, whereas Hsiao et al. (2015) showed a higher rate of asthma occurrence in T1D patients from a nationwide population-based study in Taiwan.

Cytokines play an integral role in the exacerbations of asthma and pathogenesis of T1D and mediate an inflammation along with several other inflammatory cells (Mahajan and Mehta, 2006; Rabinovitch and Suarez-Pinzon, 2007). Increased interferon-gamma (IFN- $\gamma$ ), secreted by autoreactive Th1 cells, and oversecretion of interleukin-4 (IL-4), interleukin-5 (IL-5), and interleukin-13 (IL-13) by autoreactive Th2 cells have been observed in T1D and asthma, respectively (Guo et al., 2018; Levine and Wenzel, 2010; Park et al., 2013; Mazzarella et al., 2000; Xiangyang et al., 2006). In general, the IFN- $\gamma / \mathrm{IL}-4$ ratio 
is used to define the predominant T-helper (Th) phenotype (Salvi et al., 2001). An intermediary cytokine secretary pattern that combines the features of both T1D and asthma with a unique IFN- $\gamma /$ IL-4 ratio is noticed in the patients with both these diseases (Rachmiel et al., 2006).

Flavonoids are polyphenolic plant compounds that have been extensively studied for their immunomodulatory effects in experimental models of asthma and diabetes. They have shown to inhibit the synthesis of IL-4 and its related signal transduction mechanisms in an animal model of asthma and allergy (Jurokova et al., 2015; Tanaka and Takahashi, 2013). Furthermore, these polyphenols have shown to play protective roles in glucose homeostasis by modulating the immune system (Vinayagam and $\mathrm{Xu}, 2015)$. Quercetin is a flavonol consisting of two aromatic rings that are linked by heterocyclic ring having oxygen moiety in it. Quercetin has shown to inhibit airway hypersensitivity, inflammation and mucous secretion with associated reductions in IL-4, and Th2 immune responses in ovalbumin-sensitized and challenged mice (Fortunato et al., 2012; Park et al., 2009). Furthermore, quercetin has shown to attenuate alloxan-induced hyperglycemia in mice (Zhang et al., 2016). Moreover, quercetin has shown immune modulation in several other disease conditions such as influenza A virus infection (Mehrbod et al., 2018), dengue virus infection (Jasso-Miranda et al., 2019), Japanese encephalitis virus infection (Johari et al., 2012), experimental cirrhosis (Casas-Grajales et al., 2017), rheumatoid arthritis (Al-Rekabi et al., 2015; Javadi et al., 2017), and multiple sclerosis (Sternberg et al., 2008). However, its immunomodulatory role in comorbid conditions of T1D and asthma has never been tested despite its potential to alleviate both diabetes and asthma. The previous study results indicated the presence of dysregulated and a unique Th1/Th2 cytokine balance in mice challenged with T1D and allergic asthma (Ravikumar and Kavitha, 2019). Moreover, quercetin has shown immune modulation.

In the present study, it was believed creditable to determine the immunomodulatory effect of quercetin on dysregulated Th1/Th2 immune balance in mice with both T1D and allergic asthma.

\section{MATERIALS AND METHODS}

\section{Animals}

Adult male Balb/c mice of Taconic background and having the age between 6 and 8 weeks were obtained from Vivo Bio Tech Ltd., India. Mice were acclimated for 5 days before the experimentation and were housed individually for the entire study period. The mice were provided with free access to standard rodent diet and water and were maintained on a 12-hour dark/light cycle in controlled housing conditions of temperature $\left(19^{\circ} \mathrm{C}-25^{\circ} \mathrm{C}\right)$, relative humidity $(30 \%-70 \%)$, and air changes (15-20 per hour). The animal procedures were conducted as per the approved protocol (VB/IAEC/07/2019/360/Mouse/Balb/c) by the Institutional Animal Ethics Committee (IAEC) of Vivo Bio Tech Ltd.

\section{Experimental design and treatment protocol}

After acclimatization period, based on their body weight, the mice were randomized into six groups $(n=6$ per group): (1) non-diabetic asthma + vehicle, (2) non-diabetic asthma + quercetin $10 \mathrm{mg} / \mathrm{kg}$, (3) non-diabetic asthma + quercetin $30 \mathrm{mg} /$ $\mathrm{kg}$, (4) diabetic asthma + vehicle, (5) diabetic asthma + quercetin $10 \mathrm{mg} / \mathrm{kg}$, and (6) diabetic asthma + quercetin $30 \mathrm{mg} / \mathrm{kg}$. The nondiabetic asthma group animals were induced with asthma alone, whereas diabetic asthma animals were induced with both T1D and asthma as per the procedures mentioned below. Quercetin (sourced from Bulk Supplements, Henderson, NV) was dissolved in $1 \%$ dimethyl sulfoxide (DMSO) and dosed orally on every day for 13 days from day 3 to 15 . Vehicle animals received $1 \% \mathrm{DMSO} /$ $\mathrm{kg}$ body weight orally. Daily body weights and clinical signs were noted until the end of the study.

\section{Alloxan-induced diabetes}

The mice in the diabetic groups were injected intravenously (i.v) with $80 \mathrm{mg} / \mathrm{kg}$ of alloxan monohydrate (Sigma-Aldrich, India) dissolved freshly in sterile water after a brief fasting period of 3 hours on day 0 , as described previously with slight modification (Pettersson et al., 2011). The induction of T1D was verified after 72 hours of alloxan injection by drawing blood through tail prick and checking blood glucose levels using Accu-Chek Aviva glucometer (Roche Diagnostics). The blood glucose level $>250 \mathrm{mg} / \mathrm{dl}$ was considered as T1D for the study.

\section{Ovalbumin-induced asthma}

The mice in both the non-diabetic and diabetic groups were sensitized twice on days 3 and 8 with an intraperitoneal (i.p) injection of $50 \mu \mathrm{g}$ ovalbumin (Ova) emulsified in $2.5 \mathrm{mg}$ of aluminum hydroxide $\left(\mathrm{Al}(\mathrm{OH})_{3}\right)$ in $0.2 \mathrm{ml}$ of PBS. Following sensitization, on days 13-15, all mice received an intranasal challenge with $100 \mu \mathrm{g}$ Ova in $25 \mu \mathrm{l}$ of sterile saline (4\% w/v Ova) 1 hour later to compound treatment as described previously with modifications (Carvalho et al., 2018; Fernandez-Rodriguez et al., 2008).

\section{Nasal hyperresponsiveness (NHR) evaluation}

About 24 hours after last compound treatment and following asthma induction, on day 16 , once again all the mice were challenged intranasally with $100 \mu \mathrm{g}$ Ova in $25 \mu \mathrm{l}$ of sterile saline ( $4 \% w / v$ Ova). Immediately after the last Ova challenge, the nose rubbing frequency in each mouse was counted as a measure of upper airway hyperresponsiveness as described previously (Zhang et al., 2016).

\section{Blood glucose levels and leukocyte count}

Following NHR evaluation, random blood glucose levels were estimated using Accu-Chek Aviva glucometer (Roche

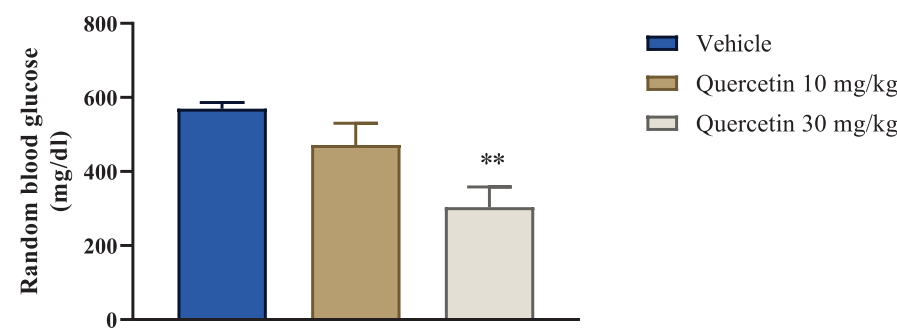

Figure 1. Alloxan-induced hyperglycemia reduces after quercetin treatment. The random blood glucose was measured using glucometer on day 16 from blood withdrawn through tail prick. Data $(n=6)$ are represented as mean \pm SEM, $* *=p<0.01$ versus vehicle. 
Diagnostics) from blood samples drawn through tail prick. Later, blood was withdrawn through retro-orbital plexus and collected one aliquot in ethylenediaminetetraacetic acid tubes and other aliquot in serum separator tubes. The total leukocyte count of the blood was assessed using a hematology analyzer (Medonic CA620), and differential leukocytes were counted manually after Giemsa staining of blood smear. The percentage of differential leukocyte count (DLC) was multiplied with total leukocyte count to derive the absolute differential leukocyte count. Serum was separated after centrifuging blood at $10,000 \mathrm{rpm}$ for 5 minutes at $4^{\circ} \mathrm{C}$ and stored at $-80^{\circ} \mathrm{C}$ for cytokine estimations using the Enzyme-linked immunosorbent assay (ELISA) kit.

\section{Bronchoalveolar lavage fluid (BALF)}

The mice were euthanized by $\mathrm{CO}_{2}$ asphyxiation immediately after blood collection, and the chest cavity was opened. A tracheal cannula was inserted, $0.8 \mathrm{ml}$ of PBS was infused into the lungs, and BALF was collected. The procedure was repeated twice to collect maximum amount of BALF. Immediately after collection, BALF was centrifuged at 2,500 rpm for 10 minutes at $4^{\circ} \mathrm{C}$, and the supernatant was collected and stored at $-80^{\circ} \mathrm{C}$ for cytokine estimations using ELISA kit. A 250 $\mu 1$ of PBS was added to the lavage pellet, and the total leukocytes were counted with Medonic CA620 hematology analyzer. The differential leukocyte counts in BALF were estimated manually after staining of BALF smear with Giemsa, and the absolute DLCs in BALF were derived by multiplying the percentage of DLC with total leukocytes in BALF.

\section{Necropsy and lung histopathology}

Gross observation of the spleen and internal organs was carried during necropsy, and the spleen weights were noted. The lungs of mice in each group $(n=2)$ were collected in $10 \%$ formalin and embedded in paraffin blocks. The sections $(4 \mu \mathrm{m})$ were made and stained with hematoxylin and eosin ( $\mathrm{H}$ and $\mathrm{E})$. The $\mathrm{H}$ and E-stained lung sections were observed for inflammatory cell aggregates and mucous cell metaplasia around airways as a measure of airway inflammation by a pathologist who was unaware of the treatment details of each group. The mucous cell metaplasia was graded as follows: $0=$ no difference, $1=$ scattered mucous cells, 2 = aggregates of mucous cells, $3=$ monolayer of mucous cells, and $4=$ multilayered mucous cells .

\section{Th1/Th2 cytokines in serum and BALF}

The level of IFN- $\gamma$ as Th1 responsive cytokine and IL-4 and IL-10 as Th2 responsive cytokines was assessed by ELISA method in both serum and BALF, following kits' manual (Invitrogen Mouse Th1/Th2 ELISA kit, cat \# 88-7711-44). The assay was conducted in 96-well format, and the ODs were obtained by reading the plate using a microplate reader (Multiskan GO, Thermo Scientific). The unknown concentrations were derived from extrapolation of the standard curve constructed using mouse IFN- $\gamma$ (assortment: $15-2,000 \mathrm{pg} / \mathrm{ml}$ ), mouse IL-4 (assortment: 4-500 pg/ml), and mouse IL-10 (assortment: 30-4,000 pg/ml).

\section{Statistical analysis}

All statistical analyses and graphs were created using GraphPad Prism 8.1 software. The data were analyzed using a one-way analysis of variance, followed by Tukey's multiple comparison test or unpaired Student's t-test wherever applicable, and the $p<0.05$ was considered to be significant.

\section{RESULTS AND DISCUSSION}

\section{Quercetin reduces alloxan-induced hyperglycemia in diabetic asthma mice}

Balb/c mice presented a significant rise in blood glucose at 72 hours (day 3 ) after single alloxan injection with a concomitant decrease in body weight, suggesting T1D state in these mice (Table 1). Quercetin treatment showed a dose-dependent decrease in alloxan-induced hyperglycemia with a significant reduction at 30 $\mathrm{mg} / \mathrm{kg}$ dose compared to the vehicle-treated diabetic asthma mice (Fig. 1). Nearly, $17 \%$ and $47 \%$ decrease in glucose were observed with 10 and $30 \mathrm{mg} / \mathrm{kg}$ doses of quercetin, respectively. The glucose reduction potential of quercetin has been widely tested and stated in quite a few animal models of diabetes (Zhang et al., 2016; Yang and Kang, 2018). Although the previous reports were all in pure diabetic models, the glucose reduction potential of quercetin in the diabetic asthma model could be related to its strong antioxidant- and $\beta$-cell-protective actions along with modulation of Th1/Th2 immune balance in these mice. In addition, quercetin at $30 \mathrm{mg} / \mathrm{kg}$ dose significantly reduced the percentage body weight loss ( $\downarrow 9.60 \%$ vs. $\downarrow 16.04 \%)$ than vehicle-treated mice (Table 2 ).

Quercetin inhibits nasal hyperresponsiveness after ovalbumin challenge in both non-diabetic and diabetic asthma mice

To understand the immunomodulatory role of quercetin, its effect on allergen-induced hyperresponsiveness was tested first. The allergen-induced allergic hyperreactivity of upper airways was assessed by measuring the number of nose rubbings as a measure of nasal hyperresponsiveness immediately after

Table 1. Hyperglycemia and body weights in diabetic asthma mice on day 3 after alloxan injection.

\begin{tabular}{lcc}
\hline Group & $\begin{array}{c}\text { Random blood glucose } \\
(\mathbf{m g} / \mathbf{d l})\end{array}$ & Body weight $(\mathbf{g})$ \\
\hline Diabetic asthma + vehicle & $382.00 \pm 50.70^{* * * *}$ & $22.58 \pm 0.60^{\wedge}$ \\
Diabetic asthma + quercetin $10 \mathrm{mg} / \mathrm{kg}$ & $376.83 \pm 46.34 * * * *$ & $23.71 \pm 0.52$ \\
Diabetic asthma + quercetin $30 \mathrm{mg} / \mathrm{kg}$ & $383.00 \pm 40.65^{* * * *}$ & $22.55 \pm 0.36^{\wedge \wedge}$ \\
\hline
\end{tabular}

Data $(n=6)$ are showed as mean \pm SEM

$* * * *=p<0.01$ against baseline random blood glucose before alloxan injection $(99.17 \pm 5.95)$ $\wedge=p<0.05$ and $\wedge^{\wedge}=p<0.01$ against basal body weight before alloxan injection $(24.29 \pm 0.39)$

Table 2. Percentage body weight change from basal and relative spleen weights in nondiabetic and diabetic asthma mice on day 16 after quercetin treatment.

\begin{tabular}{lcc}
\hline Group & $\begin{array}{c}\text { \% body weight } \\
\text { change }\end{array}$ & $\begin{array}{c}\text { Relative spleen } \\
\text { weight }(\mathbf{m g})\end{array}$ \\
\hline Nondiabetic asthma + vehicle & $3.04 \pm 1.15$ & $0.59 \pm 0.04$ \\
Nondiabetic asthma + quercetin $10 \mathrm{mg} / \mathrm{kg}$ & $3.18 \pm 1.76$ & $0.48 \pm 0.03$ \\
Nondiabetic asthma + quercetin $30 \mathrm{mg} / \mathrm{kg}$ & $1.97 \pm 1.14$ & $0.47 \pm 0.06$ \\
Diabetic asthma + vehicle & $-16.04 \pm 1.82$ & $0.35 \pm 0.04$ \\
Diabetic asthma + quercetin $10 \mathrm{mg} / \mathrm{kg}$ & $-13.15 \pm 2.91$ & $0.27 \pm 0.04$ \\
Diabetic asthma + quercetin $30 \mathrm{mg} / \mathrm{kg}$ & $-9.60 \pm 0.96 \# \#$ & $0.26 \pm 0.05$ \\
\hline
\end{tabular}

The percentage body change was calculated using the formula: (Body weight on day 16 -body weight on day 3)/body weight on day $3 * 100$.

Data $(n=6)$ are presented as mean \pm SEM.

$\# \#=0<0.01$ against diabetic asthma vehicle. 
challenge with ovalbumin. Untreated non-diabetic and diabetic mice presented almost similar NHR after Ova challenge. The nasal rubbing frequency increased because intranasal Ova challenge was significantly reduced after quercetin treatment at $30 \mathrm{mg} / \mathrm{kg}$ dose in both non-diabetic and diabetic asthma mice. Quercetin at $10 \mathrm{mg} / \mathrm{kg}$ managed to reduce the NHR at an insignificant level in Ova-sensitized and challenged mice with or without diabetes when compared to vehicle-treated mice (Fig. 2). Similar results were observed by Edo et al. (2018) using $20 \mathrm{mg} / \mathrm{kg}$ of quercetin in Ova induced allergic rhinitis model, wherein the reduction in nasal symptoms like nasal rubbing and number of sneezes were reduced. The author proposed that this nasal hyperresponsiveness reduction after quercetin oral treatment was due to increase of thioredoxin production by nasal epithelial cells, which is an antioxidant protein produced endogenously. Partially, we could hypothesize that the reduction of NHR observed after quercetin oral treatment, in this study, would have resulted through this mechanism. Partly, it could have resulted from the inhibition of allergic mediators such as histamine and leukotriene by eosinophils and mast cells (Middleton, 1998). Furthermore, the inhibitory effect of quercetin on the production of nitric oxide in vitro by human epithelial nasal cells (Ebihara et al., 2018) suggests that the antioxidant potential of quercetin may have played a role in reducing the NHR in this study. The observed efficacy of quercetin on the frequency of upper airway hyperactivity was a dose-dependent effect.

\section{Quercetin inhibits Ova-induced allergic airway inflammation in both non-diabetic and diabetic asthma mice}

The effect of quercetin on Ova-induced allergic airway inflammation was studied by measuring the inflammatory cell numbers in blood, BALF, and $\mathrm{H}$ and E-stained lung sections from samples collected 1 hour after the last Ova challenge in sensitized non-diabetic and diabetic mice. Quercetin treatment $(30 \mathrm{mg} / \mathrm{kg})$ of Ova-sensitized and challenged non-diabetic and diabetic mice demonstrated significantly low numbers of Th2 response eosinophils in BALF (Fig. 3a) and blood (Fig. 3b). In general, these outcomes are in agreement with the data published for the protective role of quercetin in ovalbumin-induced asthma (Cai et al., 2017; Rogerio et al., 2007; Sozmen et al., 2016). Furthermore, quercetin has shown to inhibit the eosinophil function and degranulation in in vitro studies after immunological stimuli

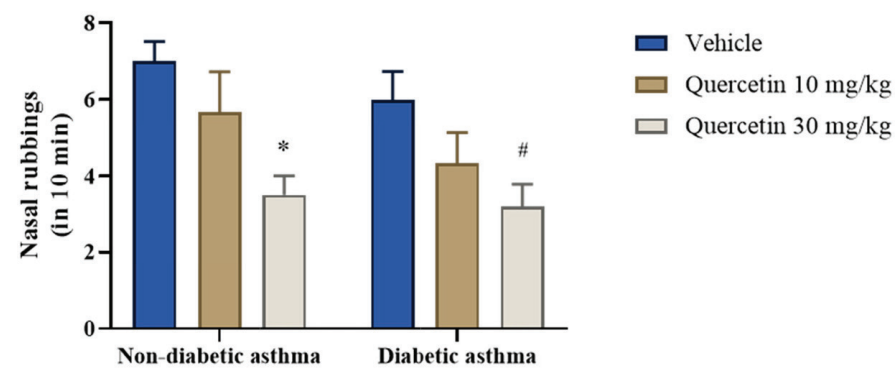

Figure 2. Frequency of upper airway allergic hyperresponses in mice after Ova challenge. The number of nasal rubbings per mice was counted for 10 minutes immediately after the last Ova challenge. Data $(n=6)$ are represented as mean \pm SEM. ${ }^{*}=p<0.05$ against nondiabetic asthma vehicle and $\#=p<0.05$ against diabetic asthma vehicle. and shown the ability to constrain the production of inflammatory cytokines by eosinophils (Sakai-Kashiwabara and Asano, 2013).

Furthermore, histopathological observation of $\mathrm{H}$ and E-stained lung sections revealed that $30 \mathrm{mg} / \mathrm{kg}$ dose of quercetin significantly reduced the mucous cell metaplasia and perivascular inflammatory cell aggregates in both the non-diabetic (Figure 3c and 3d) and diabetic (Figure 3e and 3f) asthma mice after Ova challenge. Quercetin at $10 \mathrm{mg} / \mathrm{kg}$ dose also showed improvement in asthma condition by reducing mucous cell and inflammatory cell aggregates around airways in both the non-diabetic and diabetic mice compared to untreated mice. Similarly, the observations were reported by Park et al. (2009) using quercetin in Ova model of asthma, indicating the inhibition of allergen-induced inflammation of airways including the infiltration of eosinophilic Th2 cells into lung airways.

In addition, quercetin treatment showed significantly lower graded mucous cell metaplasia per lung section in sensitized mice after Ova challenge compared to the vehicle treatment. Still, both 10 and $30 \mathrm{mg} / \mathrm{kg}$ dosages of quercetin exerted an inhibition of mucous cell metaplasia grading in comorbid diabetic asthma mice, and only $30 \mathrm{mg} / \mathrm{kg}$ dose of quercetin showed significance in the case of non-diabetic asthma mice (Fig. 3g).

\section{Quercetin modulates Th1/Th2 cytokine balance in Ova-induced allergic asthma in non-diabetic and diabetic mice}

To know the effect of quercetin on Th1/Th2 immune balance, the Th1 and Th2 cytokines were estimated in BALF and serum samples collected post 1 hour of last Ova challenge. The cytokines estimated were IFN- $\gamma$ as Th1-mediated cytokine secretion and IL-4 and IL-10 as Th2-mediated cytokine secretion. The BALF and serum cytokine levels indicated a significant upregulation of Th2 responsive IL-4 after Ova sensitization and challenge in both the non-diabetic and diabetic mice. The treatment of quercetin at $30 \mathrm{mg} / \mathrm{kg}$ dose in these mice significantly lowered the IL-4 levels (Fig. 4b and e) with a corresponding slight increase in IFN- $\gamma$ (Fig. $4 a$ and d) leading to a significant increase in Th1/Th2 (IFN- $\gamma / \mathrm{IL}-4$ ) ratio in both BALF (Fig. 4g) and serum (Fig. 4h). Quercetin at $10 \mathrm{mg} / \mathrm{kg}$ dose showed a significant reduction of serum IL-4 in non-diabetic asthma mice compared to the vehicle (Fig. 4e). This result indicated that the reduction of IL-4 triggered an airway inflammation in these mice by quercetin treatment and also suggested the immunomodulatory activity of quercetin on immune dysregulation mediated through Th1/Th2 cytokine imbalance in comorbid conditions of T1D and asthma. The more increase of Th1/Th2 ratio was observed with quercetin treatment on the occasion of comorbid diabetic asthma than in asthma alone (Fig. $4 \mathrm{~g}$ and $\mathrm{h}$ ). These results were in harmony with the outcomes by Park et al. (2009), wherein quercetin showed altered polarization of Th1/Th2 balance through GATA3 decrease and T-bet increase in murine Ova asthma model. T-bet and GATA3 are prime controlling transcription factors of T-cell differentiation, especially for Th1 and Th2 lineage responses, respectively (Kanhere et al., 2012).

Interleukin-10 levels were not affected greatly by quercetin treatment although there was a little decrease observed at both the doses in BALF (Fig. 4c) and only at $30 \mathrm{mg} / \mathrm{kg}$ dose in serum (Fig. 4f) of these mice when compared to the vehicle treatment. 
a)

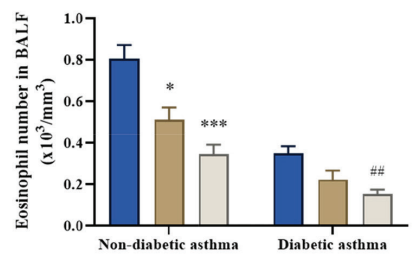

b)

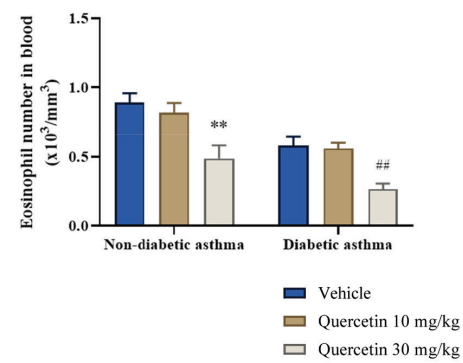

c)

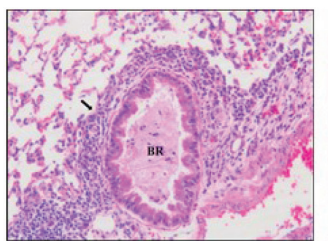

Non-diabetic asthma + Veh

d)

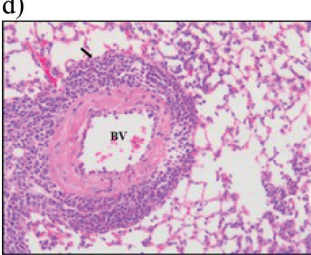

Non-diabetic asthma + Veh

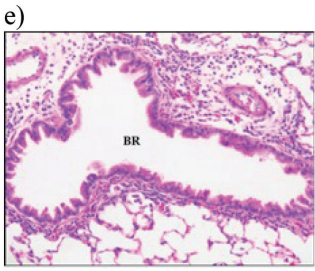

Diabetic asthma + Veh

f)

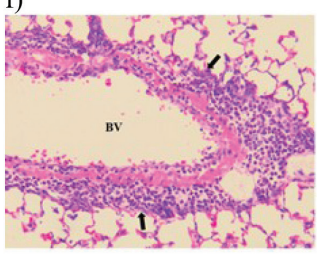

Diabetic asthma + Veh

g)

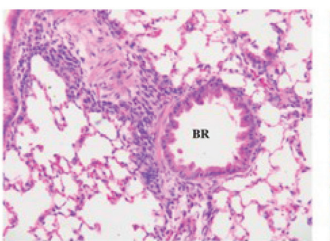

Non-diabetic asthma + Q10

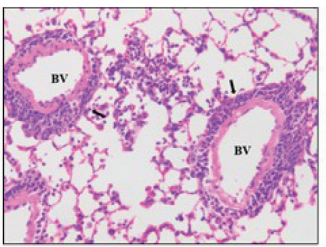

Non-diabetic asthma + Q10

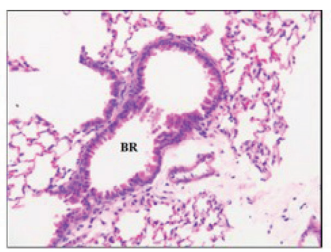

Diabetic asthma +Q10

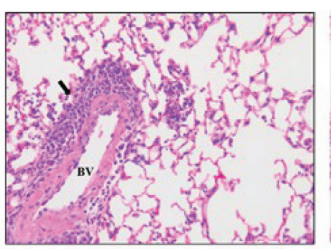

Diabetic asthma $+\mathrm{Q} 10$

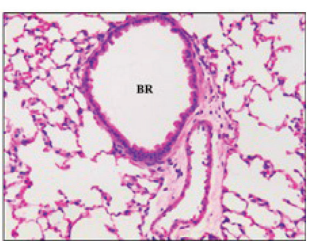

Non-diabetic asthma + Q30

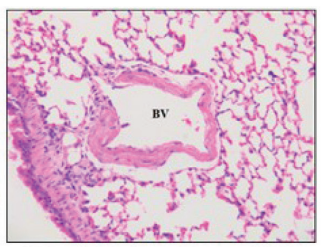

Non-diabetic asthma +Q30

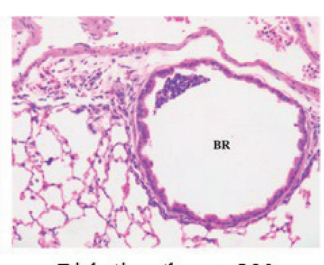

Diabetic asthma + Q30

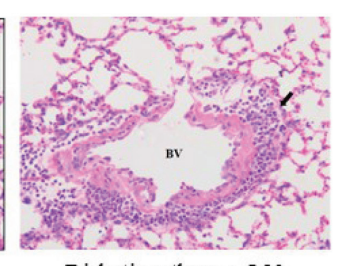

Diabetic asthma + Q30

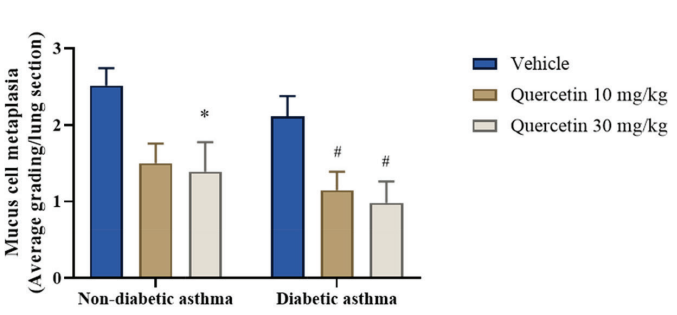

Figure 3. Decreased infiltration of Th2 responsive inflammatory cells in BALF, blood, and lung airways after quercetin treatment in diabetic mice sensitized and challenged with ovalbumin. Eosinophil cell numbers in a) BALF and b) blood collected 1 hour after the last Ova challenge. c) mucous cell metaplasia in bronchioles (BV) of nondiabetics, d) perivascular (BV) inflammatory cell aggregates in nondiabetics, e) mucous cell metaplasia in diabetics, f) perivascular inflammatory cell aggregates in diabetics, and g) average grading of mucous cell metaplasia per lung section obtained 1 hour after last Ova challenge from sensitized mice. Absolute differential leukocyte counts in BALF and blood were determined by Giemsa staining. Lung tissue inflammation was assessed by $\mathrm{H}$ and $\mathrm{E}$ staining of lung sections (magnification, $\times 200$ ). Inflammatory cell aggregation around blood vessel (BV) and mucous cell metaplasia of bronchiole (BR) in the lung sections were shown by arrow. Quercetin at $10 \mathrm{mg} / \mathrm{kg}$ and $30 \mathrm{mg} / \mathrm{kg}$ is represented as Q10 and Q30, respectively, in lung section figures. Eosinophil data $(n=5-6)$ and average graded mucous metaplasia $(n=2 ; 3$ lung sections/animal) are represented as mean \pm SEM. $*=p<0.05, * *=p<0.01$, and $* * *=p<0.001$ against non-diabetic vehicle; $\#=p<0.05$ and $\# \#=p<0.01$ against diabetic asthma vehicle. 
a)

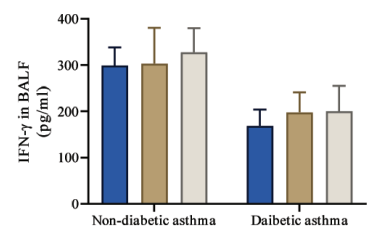

d)

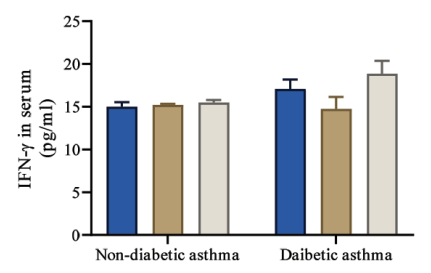

g)

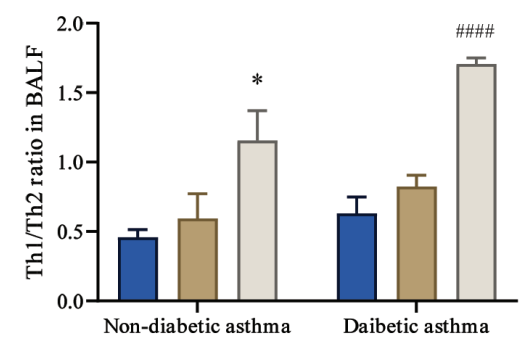

b)

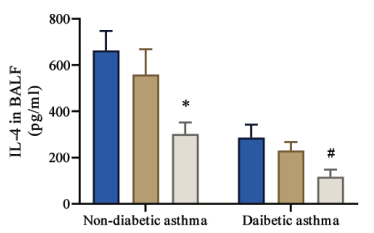

e)

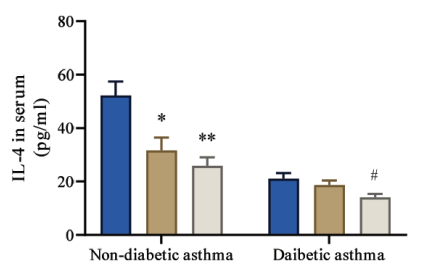

c)

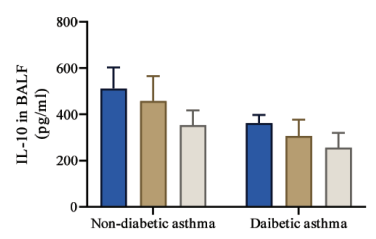

f)

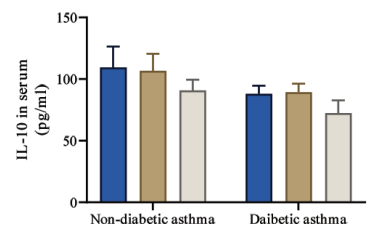

h)

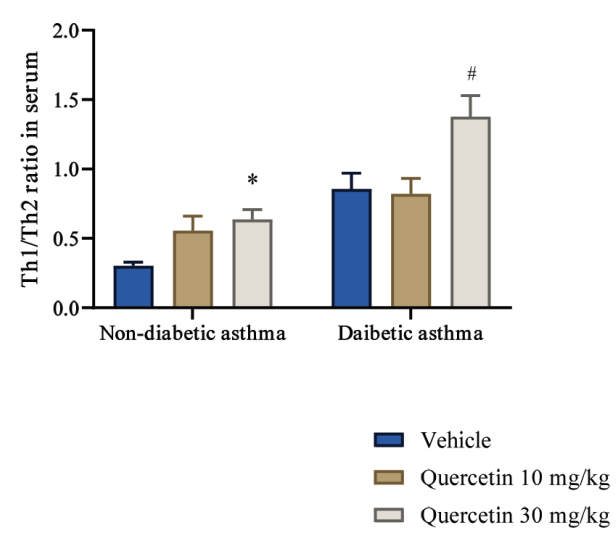

Figure 4. Th1/Th2 cytokine modulation after quercetin treatment in Ova-induced asthma in sensitized nondiabetic and diabetic mice. (a-c) BALF levels of IFN- $\gamma$, IL-4, and IL-10, respectively, at 1 hour after the last Ova challenge. d-f) Serum levels of IFN- $\gamma$, IL-4, and IL-10, respectively, at 1 hour after the last Ova challenge. ( $g$ and $h$ ) Th1/Th2 ratio in BALF and serum, respectively.

Data are represented as mean $\pm \operatorname{SEM}(n=4$ for BALF and $n=5-6$ for serum).

${ }^{*} p<0.05$ and ${ }^{* *} p<0.01$ versus nondiabetic asthma vehicle; $\# p<0.05$ and \#\#\#p $<0.0001$ versus diabetic asthma vehicle.

We believe that the present study is the first study that showcased the immunomodulatory effect of quercetin in comorbid diabetic asthma in mice. The inclusion of asthma alone (non-diabetic asthma) groups served as efficacy controls for the anti-asthmatic potential of quercetin. The quercetin treatment of both the diabetic asthma and non-diabetic asthma mice revealed dose-dependent reduction of NHR, eosinophilic Th2 cells, and Th2 responsive IL-4 levels, leading to significant inhibition of the allergic airway inflammation of lungs as evidenced by decreased mucous cell metaplasia and inflammatory cell aggregation around airways in $\mathrm{H}$ and E-stained lung sections after Ova challenge. Among the doses tested, quercetin at $30 \mathrm{mg} / \mathrm{kg}$ dose showed significant reductions in all parameters of allergic asthma in these mice. The magnitude of efficacy for quercetin at $30 \mathrm{mg} / \mathrm{kg}$ dose was similar in both comorbid diabetic asthma and asthma alone conditions, suggesting that its immunomodulatory efficacy against Th1/Th2 cytokine responses was similar in these two conditions.

\section{CONCLUSION}

The results in this study indicate that quercetin treatment significantly lowered all the asthma features in both the diabetic and non-diabetic asthma mice, indicating the therapeutic benefits of this compound in the comorbid conditions of type 1 diabetes and asthma. Moreover, quercetin showed immunomodulation in these mice by modifying the altered Th1/Th2 immune balance toward a favorable and balanced immune response, ultimately leading to the alleviation of allergic inflammation in the lungs of these mice. The modulation of Th1/Th2 immune balance in these mice after quercetin treatment was a result of not only fall in Th2 cytokine IL-4 but also due to mild rise in Th1 cytokine IFN- $\gamma$. In addition, quercetin treatment at $30 \mathrm{mg} / \mathrm{kg}$ improved glycemia and decreased body weight loss in comorbid diabetic asthma mice. Nonetheless, quercetin has offered dose-dependent improvements in both asthma and diabetic illnesses in these mice and modulated the dysregulated immune system that mediated through Th1/Th2 imbalance in these mice.

\section{ACKNOWLEDGMENTS}

The authors are grateful to Vivo Bio Tech Ltd. (Hyderabad, India) for providing the animals and laboratory research facilities for this research work. The authors are also thankful to the GITAM Institute of Pharmacy, GITAM (Deemed to be University), Visakhapatnam, for providing support to the research work. 


\section{AUTHORS' CONTRIBUTIONS}

Ravikumar $\mathrm{N}$ has carried out the experimental work and data analysis. Ravikumar $\mathrm{N}$ and Kavitha $\mathrm{CH}$. N have designed and drafted the manuscript.

\section{CONFLICT OF INTEREST} interest.

The authors declared that they have no conflict of

\section{REFERENCES}

Al-Rekabi MD, Ali SH, Al-Basaisi H, Hashim F, Hussein AH, Abbas HK. Immunomodulatory effects of quercetin in patient with active rheumatoid arthritis. Br J Med Health Res, 2015; 2(6):23-34.

Cai Y, Wang L, Zhang X, Liu H. Quercetin inhibits airway allergic inflammation through inhibiting the expression of NF- $\kappa \mathrm{B}$ activator 1. Int J Clin Exp Med, 2017; 10(6):9238-44.

Cardwell CR, Shields MD, Carson DJ, Patterson CC. A metaanalysis of the association between childhood type 1 diabetes and atopic disease. Diabetes Care, 2003; 26(9):2568-74.

Carvalho VF, Barreto EO, Arantes ACS, Serra MF, Ferreira TPT, Jannini-Sa YAP, Hogaboam CM, Martins MA, Silva PMR. Diabetes downregulates allergen-induced airway inflammation in mice. Mediators Inflamm, 2018; 1-11.

Casas-Grajales S, Vazquez-Flores LF, Ramos-Tovar E, Hernandez-Aquino E, Flores-Beltran RE, Cerda-Garcia-Rojas CM, Camacho J, Shibayama M, Tsutsumi V, Muriel P. Quercetin reverses experimental cirrhosis by immunomodulation of the proinflammatory and profibrotic processes. Fund Clin Pharmacol, 2017; 31(6):610-24.

Ebihara N, Takahashi K, Takemura H, Akanuma Y, Asano K, Sunagawa M. Suppressive effect of quercetin on nitric oxide production from nasal epithelial cells in vitro. Evid Based Complement Alternat Med, 2018; article ID. 6097625.

Edo Y, Otaki A, Asano K. Quercetin enhances the thioredoxin production of nasal epithelial cells in vitro and in vivo. Medicines, 2018; 5(124):1-12.

Fernandez-Rodriguez S, Ford WR, Broadley KJ, Kidd EJ. Establishing the phenotype in novel acute and chronic murine models of allergic asthma. Int Immunopharmacol, 2008; 8:756-63.

Fortunato LR, Alves CDF, Teixeira MM, Rogerio AP. Quercetin: A flavonoid with the potential to treat asthma. Braz J Pharm Sci, 2012; 48(4):589-99.

Guo Y, Xiao Z, Wang Y, Yao W, Liao S, Yu B, Zhang J, Zhang Y, Zheng B, Ren B, Gong Q. Sodium butyrate ameliorates streptozotocininduced type 1 diabetes in mice by inhibiting the HMGB1 expression. Front Endocrinol, 2018; 9:1-9.

Hsiao YT, Cheng WC, Liao WC, Lin CL, Shen TC, Chen WC, Chen $\mathrm{CH}$, Kao $\mathrm{CH}$. Type 1 diabetes and increased risk of subsequent asthma: a nationwide population-based cohort study. Medicine, 2015; 94(36): $1-6$

Jasso-Miranda C, Herrera-Camacho I, Flores-Mendoza LK, Dominguez F, Vallejo-Ruiz V, Sanchez-Burgos GG, Pando-Robles V, Santos-Lopez G, Reyes-Leyva J. Antiviral and immunomodulatory effects of polyphenols on macrophages infected with dengue virus serotypes 2 and 3 enhanced or not with antibodies. Infect Drug Resist, 2019; 12:1833-52.

Javadi F, Ahmadzadeh A, Eghtesadi S, Aryaeian N, Zabihiyeganeh M, Foroushani AR, Jazayeri S. The effect of quercetin on inflammatory factors and clinical symptoms in women with rheumatoid arthritis: a double-blind, randomized controlled trial. J Am Coll Nutr, 2017; 36(1):9-15.

Johari J, Kianmehr A, Mustafa MR, Abubakar S, Zandi K. Antiviral effect of baicalein and quercetin against the Japanese encephalitis virus. Int J Mol Sci, 2012; 13:16785-95.

Jurokova T, MIcek J, Sochor J, Hegedusova A. Polyphenols and their mechanism of action in allergic immune response. Glob J Allergy, 2015; 1(2):037-9.
Kanhere A, Hertweck A, Bhatia U, Gokmen MR, Perucha E, Jackson I, Lord GM, Jenner RG. T-bet and GATA3 orchestrate Th1 and Th2 differentiation through lineage-specific targeting of distal regulatory elements. Nat Commun, 2012; 3(1268):1-12.

Levine SJ, Wenzel SE. The role of Th2 immune pathway modulation in the treatment of severe asthma and its phenotypes: Are we getting closer? Ann Intern Med, 2010; 152(4):232-7.

Mahajan S, Mehta AA. Role of cytokines in pathophysiology of asthma. Iran J Pharmacol Ther, 2006; 5(1):1-14.

Mazzarella G, Bianco A, Catena E, De Palma R, Abbate GF. Th1 Th2 lymphocyte polarization in asthma. Allergy, 2000; 55(suppl. 61):6-9.

Mehrbod P, Abdalla MA, Fotouhi F, Heidarzadeh M, Aro AO, Eloff JN, McGaw LJ, Fasina FO. Immunomodulatory properties of quercetin-3-O- $\alpha$-L-rhamnopyranoside from Rapanea melanophloeos against influenza a virus. BMC Complem Altern Med, 2018; 18:184.

Metsala J, Lundqvist A, Virta LJ, Kaila M, Gissler M, Virtanen SM, Nevalainen J. The association between asthma and type 1 diabetes: A paediatric case-cohort study in Finland, years 1981-2009. Int J Epidemiol, 2018; 47(2):409-16.

Middleton E. Effect of plant flavonoids on immune and inflammatory cell function. Adv Exp Med Biol, 1998; 439:175-82.

Park H, Lee CM, Jung ID, Lee JS, Jeong Y, Chang JH, Chun SH, Kim MJ, Choi IW, Ahn SC, Shin YK, Yeom SR, Park YM. Quercetin regulates Th1/Th2 balance in a murine model of asthma. Int Immunopharmacol, 2009; 9:261-7.

Park JH, Jung JH, Yang JY, Kim HS. Olive leaf down-regulates the oxidative stress and immune dysregulation in streptozotocin-induced diabetic mice. Nutr Res, 2013; 33:942-51.

Pettersson US, Christoffersson G, Massena S, Ahl D, Jansson L, Henriksnas J, Phillipson M. Increased recruitment but impaired function of leukocytes during inflammation in mouse models of type 1 and type 2 diabetes. PLoS One, 2011; 6(7):e22480.

Rabinovitch A, Suarez-Pinzon WL. Role of cytokines in the pathogenesis and therapy of type 1 diabetes. Cell Biochem Biophys, 2007; 48:159-63.

Rachmiel M, Bloch O, Bistritzer T, Weintrob N, Ofan R, Koren-Morag N, Rapoport MJ. Th1/Th2 cytokine balance in patients with both type 1diabetes mellitus and asthma. Cytokine, 2006; 34:170-6.

Ravikumar N, Kavitha CHN. Role of dexamethasone on immune dysregulation mediated through $\mathrm{Th} 1 / \mathrm{Th} 2$ cytokine balance in mice challenged with type 1 diabetes and allergic asthma. Int J Res Pharm Sci, 2019; 10(4):3042-54.

Rogerio AP, Kanashiro A, Fontanari C, da Silva EVG, Lucisano-Valim YM, Soares EG, Faccioli LH. Anti-inflammatory activity of quercetin and isoquercitrin in experimental murine allergic asthma. Inflamm Res, 2007; 56:402-8.

Rottem M, Shoenfeld Y. Asthma as a paradigm for autoimmune disease. Int Arch Allergy Immunol, 2003; 132:210-4.

Sakai-Kashiwabara M, Asano K. Inhibitory action of quercetin on eosinophil activation in vitro. Evid Based Complement Alternat Med, 2013; article ID. 127105.

Salvi SS, Babu KS, Holgate ST. Is asthma really due to a polarized $\mathrm{T}$ cell response toward a helper $\mathrm{T}$ cell type 2 phenotype? Am J Respir Crit Care Med, 2001; 164:1343-6.

Sozmen SC, Karaman M, Micili SC, Isik S, Bagriyanik A, Ayyildiz ZA, Uzuner N, Anal O, Karaman O. Effects of quercetin treatment on epithelium-derived cytokines and epithelial cell apoptosis in allergic airway inflammation mice model. Iran J Allergy Asthma Immunol, 2016; 15(6):487-97.

Stene LC, Nafstad P. Relation between occurrence of type 1 diabetes and asthma. Lancet, 2001; 357:607-8.

Sternberg Z, Chadha K, Lieberman A, Hojnacki D, Drake A, Zamboni P, Rocco P, Grazioli E, Weinstock-Guttman B, Munschauer F. Quercetin and interferon beta modulate immune response(s) in peripheral blood mononuclear cells isolated from multiple sclerosis patients. J Neuroimmunol, 2008; 205(1-2):142-7. 
Tanaka T, Takahashi R. Flavonoids and asthma. Nutrients, 2013; 5:2128-43.

Vinayagam R, Xu B. Antidiabetic properties of dietary flavonoids: a cellular mechanism review. Nutr Metab, 2015; 12(60):1-20.

Xiangyang Q, Weijun C, Liegang L, Ping Y, Bijun X. Effect of a Siraitia grosvenori extract containing mogrosides on the cellular immune system of type 1 diabetes mellitus mice. Mol Nutr Food Res, 2006; 50:732-8.

Yang DK, Kang HS. Anti-diabetic effect of cotreatment with quercetin and resveratrol in streptozotocin-induced diabetic rats. Biomol Ther, 2018; 26(2):130-8.

Zhang Y, Dong H, Wang M, Zhang J. Quercetin isolated from Toona sinensis leaves attenuates hyperglycemia and protects hepatocytes in high-carbohydrate/high fat diet and alloxan induced experimental diabetic mice. J Diabetes Res, 2016; article ID. 8492780.

Zhang Z, Shi L, Pang W, Liu W, Li J, Wang H, Shi G. Dietary fiber intake regulates intestinal microflora and inhibits ovalbumin- induced allergic airway inflammation in a mouse model. PLoS One, 2016; 11(2): 0147778

Zoka A, Muzes G, Somogyi A, Varga T, Szeman B, Al-Aissa Z, Hadarits O, Firneisz G. Altered immune regulation in type 1 diabetes. Clin Dev Immunol, 2013; article ID. 254874.

\section{How to cite this article:}

Ravikumar N, Kavitha CN. Immunomodulatory effect of Quercetin on dysregulated Th1/Th2 cytokine balance in mice with both type 1 diabetes and allergic asthma. J Appl Pharm Sci, 2020; 10(03):080-087. 